\title{
Evaluation of soil fertility in the succession of karst rocky desertification using principal component analysis
}

\author{
L. W. Xie ${ }^{1}$, J. Zhong ${ }^{1}$, F. F. Chen ${ }^{1}$, F. X. Cao ${ }^{2}$, J. J. Li ${ }^{1}$, and L. C. Wu ${ }^{1}$ \\ ${ }^{1}$ Key Laboratory of Cultivation and Protection for Non-Wood Forest Trees, Ministry of Education, Central South University \\ of Forestry and Technology, Changsha 410004, Hunan, China \\ ${ }^{2}$ College of Life Science and Technology, Central South University of Forestry and Technology, Changsha 410004, Hunan, \\ China
}

Correspondence to: L. C. Wu (wulichao@sina.com)

Received: 10 November 2014 - Published in Solid Earth Discuss.: 18 December 2014

Revised: 23 April 2015 - Accepted: 24 April 2015 - Published: 21 May 2015

\begin{abstract}
Expanding of karst rocky desertification (RD) area in southwestern China is strangling the sustainable development of local agricultural economy. It is important to evaluate the soil fertility at RD regions for the sustainable management of karst lands. The changes in 19 different soil fertilityrelated variables along a gradient of karst rocky desertification were investigated in five different counties belonging to the central Hunan province in China. We used principal component analysis method to calculate the soil data matrix and obtained a standardized integrate soil fertility (ISF) indicator to reflect RD grades. The results showed that the succession of RD had different impacts on soil fertility indicators. The changing trend of total organic carbon (TOC), total nitrogen (TN), available phosphorus, microbial biomass carbon (MBC), and microbial biomass nitrogen (MBN) was potential $\mathrm{RD}(\mathrm{PRD})>$ light $\mathrm{RD}(\mathrm{LRD})>$ moderate $\mathrm{RD}(\mathrm{MRD})$ $>$ intensive RD (IRD), whereas the changing trend of other indicators was not entirely consistent with the succession of RD. The degradation trend of ISF was basically parallel to the aggravation of $\mathrm{RD}$, and the strength of ISF mean values were in the order of PRD > LRD > MRD > IRD. The TOC, $\mathrm{MBC}$, and MBN could be regarded as the key indicators to evaluate the soil fertility.
\end{abstract}

\section{Introduction}

Karst rocky desertification (RD) is a process of karst land degradation involving serious soil erosion, extensive exposure of bedrock, and the appearance of a desert-like landscape, leading to drastic decrease in soil productivity (Wang et al., 2004b). Some mountain areas of central Hunan province, China, which are included in the largest karst geomorphologic distributing areas in southwestern China, were covered with evergreen broad-leaved forest historically but now are under deforestation and over-reclamation (Huang and Cai, 2007; Xiong et al., 2009). Climate changes and anthropogenic driving forces (land overuse) are responsible for the development of aeolian/sandy desertification (Wang et al., 2013a; Wang et al., 2013b) which can cause dust storms (Wang and Jia, 2013) and soil and water losses (Cerdà and Lavée, 1999) and also play important roles in the aggravation of karst rocky desertification (Li et al., 2009b; Yan and Cai, 2015). This has gradually attracted nation-wide attention in China, so that the government and researchers are taking active measures to meliorate rocky desertification land through sustainable management (Bai et al., 2013; Huang et al., 2008). For example, during the investigation of stands, we found that some karst regions with higher grades (moderate RD (MRD) or intensive RD (IRD)) had been enclosed for afforestation. This measure is beneficial to rehabilitation and sustainable management of karst lands (Jaiyeoba, 2001).

In the process of sustainable management it is important to determine the status of soil fertility on karst regions (Deng and Jiang, 2011; Li et al., 2013), because the soil fertility is 
of fundamental importance for agricultural production and soil fertility management (irrigation, fertilization, and cultivation) (Fallahzade and Hajabbasi, 2012), and it is also a central issue in the decisions on food security, poverty reduction, and environment management (Tilman et al., 2002). Soil fertility is a major component of soil quality, so investigation of soil fertility could be regarded as an essential prerequisite for the rational management and utilization of karst lands. However, soil fertility changes associated with the succession of RD in the karst lands have been poorly understood (Wang and $\mathrm{Li}, 2007$ ) due to the lack of methods for evaluating the soil on areas affected by succession of RD. The changing process of karst land from one grade to another is called "succession of RD" here (Xie and Wang, 2006), which refers to an observable process of changes of karst ecosystem such as vegetation type, vegetation coverage, bedrock exposure, and soil depth from potential RD (PRD) to IRD or vice versa. Moreover, using a minimum data set to reduce the cost for determining a broad range of indicators is vital to assess soil fertility (Yao et al., 2013) of karst lands during succession of RD.

The soil fertility depends on local climate, soil-forming conditions, environment, and anthropogenic influence in different regions (Liu et al., 2006). Choosing appropriate indicators is vital to evaluate soil fertility. Generally, evaluating indicators are chosen empirically based on the researching fruits of predecessors. However, the adaptability of soil fertility indicators to karst area should be paid close attention due to its fragile ecosystem (Fu et al., 2010). Based on the analyses of literatures (Li et al., 2007; Yao et al., 2013) and suggestions from experts on the stands investigation, we evaluated soil fertility of karst lands using 19 selected indicators.

The objectives of this work were (i) to clarify how 19 selected soil fertility indicators are affected by the succession of rocky desertification, (ii) to identify some reasonable and sensitive indicators to evaluate soil fertility of karst lands with different RD grades, and iii) to find an integrate indicator to evaluate fertility in lands with different RD grades.

\section{Materials and methods}

\subsection{Study area}

The sampling sites are in a karst region in five counties, namely Lianyuan (LY), Longhui (LH), Shaodong (SD), Xinhua $(\mathrm{XH})$, and Xinshao (XS), approximately ranging from $26^{\circ} 55^{\prime}$ to $28^{\circ} 18^{\prime} \mathrm{N}$ and $110^{\circ} 40^{\prime}$ to $112^{\circ} 05^{\prime} \mathrm{E}$ in the central Hunan province, China. Carbonate rocks and granite cover the most area, while non-carbonate rocks account for $11 \%$ of the total area. According to the Chinese Soil Taxonomy system, the major soil types are red soil and purple soil. The vegetation in these areas are mostly covered with sparse shrub grass embellished with timber and non-wood forests, such as Magnoliaceae, Lauraceae, Theaceae, Hamamelidaceae,
Eucalyptus spp., Michelia macclurei, Bambusa textilis, and Sinocalamus latiflorus. Topographic features of this region include karst landforms and fluvial erosion landforms, characterized by hills, syncline valleys, and mountains. The region is a subtropical warm, moist climate with mean annual air temperature of $18.3^{\circ} \mathrm{C}$ and with mean annual precipitations of $1425 \mathrm{~mm}$ from 2000 to 2012, which were obtained from China Meteorological Data Sharing Service System online (http://cdc.cma.gov.cn/home.do).

\subsection{Soil sampling and handling}

We used a core cutter ( $5 \mathrm{~cm}$ diameter) to take the soil samples before covering the holes carefully in the field. There were no endangered or protected species involved in this study. The permissions for sampling locations were approved by the forestry bureaus of Lianyuan, Longhui, Shaodong, Xinhua, and Xinshao counties.

To enforce the sustainable management of karst lands, in 2011 the report Monitoring Rules of Rocky Desertification in Hunan Province was issued by Hunan Provincial Bureau of Forestry, in which rocky desertification was classified into four grades, namely PRD, light RD (LRD), MRD, and IRD based on the soil depth, vegetation coverage, vegetation type, and bedrock exposure (Table 1) according to some reported classification methods (Wang et al., 2004a; Xiong et al., 2009). A given RD grade should simultaneously satisfy the pre-established ranges for two out of three variables (soil depth, vegetation coverage, and bedrock exposure). From 15 to 22 December 2011, four typical plots with different RD grades every county were selected as the sampling sites, guided by the officials at the local Forestry Bureau. The plots, designated LY1-LY4, LH1-LH4, SD1SD4, XH1-XH4, and XS1-XS4 (Table 1), were all approximately $400 \mathrm{~m}^{2}$ in area. At each sampling plot, using a grid design, six points were evenly distributed by walking like the letter " $S$ " over the area. And at each point, three cores $(5 \mathrm{~cm}$ diameter, $0-20 \mathrm{~cm}$ depth) were taken from three vertices of one triangle patch $(0.5 \mathrm{~m}$ side length). After plant debris, roots, and stones were removed, these three cores were mixed thoroughly in a clean pail without sieving to give one composite sample. Thus, totally 120 soil samples (six samples per plot, four plots each county) were collected in the field work. Every composite sample was divided into two parts, a field-moist sample and an air-dried one. The field-moist samples were kept in refrigerator under $-20^{\circ} \mathrm{C}$ before culturing the microbe to count bacteria (BAC), fungi (FUN), and actinomycetes (ACT) and analyzing the microbial biomass carbon (MBC), microbial biomass nitrogen (MBN), and microbial biomass phosphorus (MBP). The air-dried samples were used to determinate chemical and physical parameters. 
Table 1. Classification of rocky desertification and basic information of plots.

\begin{tabular}{lllcccc}
\hline Grade & Vegetation & $\begin{array}{l}\text { Land } \\
\text { use }\end{array}$ & $\begin{array}{c}\text { Soil depth } \\
/ \mathrm{cm}\end{array}$ & $\begin{array}{c}\text { Vegetation coverage } \\
1 \%\end{array}$ & $\begin{array}{c}\text { Bedrock exposure } \\
1 \%\end{array}$ & $\begin{array}{l}\text { Serial no. } \\
\text { of plots }\end{array}$ \\
\hline PRD & tree & forest conservation & $>40$ & $>70$ & $<30$ & LH1, LY1, SD1, XH1, XS1 \\
LRD & tree, shrub & timber stands, non-wood forests & $30-40$ & $50-70$ & $30-39$ & LH2, LY2, SD2, XH2, XS2 \\
MRD & shrub & non-wood forest, abandoned land & $20-29$ & $30-49$ & $40-49$ & LH3, LY3, SD3, XH3, XS3 \\
IRD & grass & abandoned land & $10-19$ & $20-29$ & $50-69$ & LH4, LY4, SD4, XH4, XS4 \\
\hline
\end{tabular}

PRD, LRD, MRD, and IRD are potential, light, moderate, and intensive rocky desertification, respectively.

\subsection{Soil physicochemical properties analyses}

Soil $\mathrm{pH}$ was determined using a combined glass electrode with $1: 2.5(w: v)$ ratio of soil to $1 \mathrm{~mol} \mathrm{~L}^{-1} \mathrm{KCl}$ in distilled water. Bulk density (BD), capillary moisture capacity $(\mathrm{CMC})$, field moisture capacity (FMC), capillary porosity (CAP), and total porosity (TOP) were determined by core cutter method. Vegetation coverage was measured on site using digital camera method after calculating the ratio of red to near-infrared brightness of image recorded and processed (Hu et al., 2007; White et al., 2000). Based on calculating the ratio of bedrock area to whole image (Hu et al., 2007; White et al., 2000), bedrock exposure was estimated using dimension measurements on site using a Nikon DTM322 total station surveying instrument (Nikon-Trimble Co. Ltd., Japan). Cation exchange capacity (CEC) was determined after saturating the exchange sites with an index cation $\left(\mathrm{NH}_{4}^{+}\right)$. This involved initial addition of $1 \mathrm{~mol} \mathrm{~L}^{-1} \mathrm{NH}_{4} \mathrm{OAc}$ at $\mathrm{pH} 8.2$ (Bower et al., 1952), washing the soil free of excess salt, displacing the adsorbed index cation $\left(\mathrm{NH}_{4}^{+}\right)$with $\mathrm{NaCl}$, and measuring the amount of index cation displaced using Kjeldahl determination method directly (Brookes et al., 1985a).

Total organic carbon (TOC) content was measured by dichromate oxidation method (Yeomans and Bremner, 1988). Total nitrogen (TN) was measured by Kjeldahl determination method after digestion (Brookes et al., 1985a). Total phosphorus (TP) and total potassium (TK) contents were measured after fusion pretreatment with sodium hydroxide (Smith and Bain, 1982). Available phosphorus (AP) and available potassium (AK) were tested using Mehlich 3 extracting method (Sims, 1989).

\subsection{Soil microbial biomass properties analyses}

Measurements of MBC, MBN, and MBP were tested by chloroform-fumigation method (Brookes et al., 1985b; Wu et al., 1990). The density of soil microorganisms including BAC, FUN, and ACT were measured by dilution plating method (Bulluck Iii et al., 2002).

\subsection{Statistical analyses}

All statistical analyses were performed using SPSS Statistics (v. 20, IBM, USA). Differences in soil fertility indicators among different RD grades were analyzed using one- way analysis of variance (ANOVA). If there was significant difference, post hoc tests (Bonferroni correction) (García, 2004; Rice, 1989) were used. Assumptions of ANOVA were checked. If equal variance could not be assumed between four RD grades, a further Brown-Forsythe test was done instead of ANOVA.

\subsection{Procedure for evaluating soil fertility using principal component analysis (PCA)}

\subsubsection{Standardization of original variables and computation of correlation matrix}

Data should be standardized to avoid unexpected influence appearing (Liu et al., 2003) because some of the 19 selected indicators were on very different scales. Data standardization can be done facilely in SPSS using the equation $x_{i j}^{\prime}=\left(x_{i j}-\bar{x}_{i}\right) / S_{i}$, where $x_{i j}^{\prime}$ is the standardized value for each indicator; $x_{i j}$ is the original value for each indicator; $\bar{x}_{i}$ is the mean of original value for each indicator; $S_{i}$ is the standard deviation for each indicator; $i=1,2, \ldots, m$ (number of indicators), herein $m=19$; and $j=1,2, \ldots, n$ (number of samples), herein $n=20$. Then, the standardized means of 19 indicators for 20 plots were ready to compute the correlation matrix.

\subsubsection{Identification of principal components}

In order to avoid information overlapping from highdimensional data sets, dimension reduction is usually performed to get a minimum data set. PCA is regarded as a statistical procedure using dimension reduction to convert a set of observations with possibly correlated variables into a set of linearly uncorrelated variables called principal components (Liu et al., 2003). A principal component is a linear combination of all original indicators; their loading coefficients are named characteristic vectors. Although the number of principal components is equal to that of indicators, which are likely not the original indicators, all principal components are not correlated to each other. Generally, the first several principal components can represent major information of the samples. The selecting rule for principal components is that (a) the eigenvalue of each principal component is bigger than 1 and (b) the cumulative variance proportion of all principal components is more than $85 \%$. 


\subsubsection{Calculation of principal component scores}

Principal component scores of all samples were obtained using the equation $\boldsymbol{P}_{k j}=\sum_{i=1}^{m} \boldsymbol{A}_{k i} \times x_{i j}^{\prime}$, where $\boldsymbol{A}_{k i}$ is the characteristic vector based on standardized data matrix; $x_{i j}^{\prime}$ is the standardized value of evaluating indicators; $k=1,2, \ldots, p$ (number of selected principal components according to the rule above); $i=1,2, \ldots, m$ (number of indicators, herein $m=17$ ); and $j=1,2, \ldots, n$ (number of samples), herein $n=20$.

\subsubsection{Calculation of integrate fertility scores}

Integrate soil fertility (ISF) scores were calculated using the equation $F_{j}=\sum_{k=1}^{p} \mathrm{VAR}_{k} \times \boldsymbol{P}_{k j}$, where $\mathrm{VAR}_{k}$ is the variance contribution rate for each principal component, i.e., the percentage of the variance for each principal component in the sum of all variances, which means the proportion of information out of the whole sample information derives from original indicators to each principal component; $\boldsymbol{P}_{k j}$ is the principal component score; $k=1,2, \ldots, p$ (number of principal components); and $j=1,2, \ldots, n$ (number of samples).

\section{Results}

\subsection{Variation of soil fertility indicators with succession of RD}

The results indicated that the succession of RD affected 19 selected soil fertility indicators to a different extent (Table 2). The content of total organic carbon, TN, MBC, MBN, and AP decreased with the aggravation of $\mathrm{RD}(p<0.05)$. TOC, TN, MBC, and MBN values for PRD were significantly different from those for LRD, MRD, and IRD, while the difference between those values for LRD and MRD was not significant. There were significant differences between TP of PRD with that of IRD and between AP of PRD with that of LRD or IRD. The changing trend of MBP, BAC, and ACT was PRD > MRD > LRD > IRD. There were significant difference between MBP for MRD and those for PRD, LRD, and IRD. The changing trend of BD was IRD > LRD > MRD $>$ PRD without obvious difference.

\subsection{Evaluation of soil fertility using PCA}

As shown in Table 3, total organic carbon, TN, and TP showed significant and positive correlation with each other, and TOC was highly correlated to TN with $r=0.936$. MBC and MBN also significantly and positively correlated to each other. Both CMC and FMC were correlated to TP, AP, TK, CEC, BD, and CAP. However, pH, AK, BAC, FUN, and ACT showed nearly no correlation with other indicators. It was notable that the correlation coefficient of BD vs. TOP is -1.000 because the TOP was calculated from BD data. Thus, we could remove TOP and TN from the data set of measurements by following principal component analysis.

PCA was performed using the data matrix of standardized means of 17 indicators, and 17 original indicators (excluding TN and TOP) were grouped into 17 independent principal components. Each eigenvalue of the first six principal components $\left(\mathrm{PC}_{1}-\mathrm{PC}_{6}\right)$ was bigger than 0.9 , and their cumulative variance proportion was $82.7 \%$, a little less than $85 \%$ (Table 4). Taken altogether, the first six principal components could represent the total information of original variables.

The order in which the principal components were interpreted depended on the magnitude of their eigenvalues. The $\mathrm{PC}_{1}$ explained $29.2 \%$ of the variance (Table 4$)$. It had highly positive loadings from CAP (0.922), CMC (0.818), FMC $(0.800)$, and TK $(0.690)$. In a rough sense, the $\mathrm{PC}_{1}$ was identified as the "water/air permeability and water-holding capacity component" since it mainly covered features related to water and air permeability and water-holding capacity of soil. The $\mathrm{PC}_{2}$ explained $19.2 \%$ of the variance with highly positive loadings from CEC (0.864) and BAC (0.772), so we defined $\mathrm{PC}_{2}$ as "cation exchangeable capacity and bacteria component".

The $\mathrm{PC}_{3}$ was defined as the "microbial biomass and organic matter component" because it explained $11.1 \%$ of the variance with positive loadings from MBC (0.874), MBN (0.861), TOC (0.674), and MBP (0.549). Explaining 9.5\% of the variance, the $\mathrm{PC}_{4}$ was called the "microbial communities component" because it had positive loading from ACT (0.784) and FUN (0.775).

The $\mathrm{PC}_{5}$ explained $8.1 \%$ of the variance and was defined as the "phosphorus nutrient component" because it had positive loading from TP (0.662). The $\mathrm{PC}_{6}$ explained $5.7 \%$ of the variance and was referred to as the "potassium nutrient component" because it had positive loading from AK (0.946).

After computing principal component scores, ISF scores of 20 plots were calculated (Fig. 1). The fertility levels of sampling sites LY1 and SD1 for PRD were higher than those of other sites as expected, but ISF scores of LH1, XH1, and XS1 for PRD were lower than ISF scores of LH2 and LY2 for LRD and ISF score of XH3 for MRD. ISF scores of LY4 and SD4 for IRD were lower than those of other sites. In summary, ISF scores fluctuated with different sampling sites for different RD grades.

To facilitate comparison, the means of ISF scores were calculated (Fig. 2). The sequencing of the mean ISF scores was $\mathrm{PRD}>\mathrm{LRD}>\mathrm{MRD}>\mathrm{IRD}$. Only the difference between ISF scores of MRD and those of IRD was significant $(p=0.041)$. The ISF scores of PRD vs. LRD $(p=0.111)$, PRD vs. MRD ( $p=0.254)$, PRD vs. IRD ( $p=0.097)$, LRD vs. MRD $(p=0.726)$, and LRD vs. IRD $(p=0.229)$ were not significantly different. 
Table 2. Effects of succession of rocky desertification on soil fertility indicators.

\begin{tabular}{|c|c|c|c|c|}
\hline Test items & PRD & LRD & MRD & IRD \\
\hline $\mathrm{pH}$ & $5.72 \pm 1.26 \mathrm{a}$ & $6.18 \pm 1.09 \mathrm{a}$ & $6.55 \pm 0.64 \mathrm{a}$ & $6.16 \pm 0.10 \mathrm{a}$ \\
\hline TOC $\left(\mathrm{g} \mathrm{kg}^{-1}\right)$ & $27.50 \pm 4.30 \mathrm{a}$ & $25.32 \pm 7.97 b$ & $19.10 \pm 1.42 b$ & $16.86 \pm 2.99 \mathrm{c}$ \\
\hline $\mathrm{TN}\left(\mathrm{g} \mathrm{kg}^{-1}\right)$ & $2.64 \pm 0.40 \mathrm{a}$ & $2.31 \pm 0.87 b$ & $1.77 \pm 0.15 b$ & $1.41 \pm 0.41 \mathrm{c}$ \\
\hline $\mathrm{TP}\left(\mathrm{g} \mathrm{kg}^{-1}\right)$ & $0.58 \pm 0.05 \mathrm{a}$ & $0.45 \pm 0.21 \mathrm{ab}$ & $0.39 \pm 0.06 \mathrm{ab}$ & $0.43 \pm 0.14 b$ \\
\hline $\mathrm{AP}\left(\mathrm{mg} \mathrm{kg}^{-1}\right)$ & $1.37 \pm 0.49 \mathrm{a}$ & $1.12 \pm 0.90 \mathrm{~b}$ & $0.60 \pm 0.45 \mathrm{ab}$ & $0.19 \pm 0.11 \mathrm{c}$ \\
\hline $\mathrm{TK}\left(\mathrm{g} \mathrm{kg}^{-1}\right)$ & $8.67 \pm 4.52 \mathrm{a}$ & $10.90 \pm 5.28 \mathrm{a}$ & $12.33 \pm 8.09 a$ & $11.83 \pm 2.84 b$ \\
\hline $\mathrm{AK}\left(\mathrm{mg} \mathrm{kg}^{-1}\right)$ & $95.60 \pm 22.13 \mathrm{a}$ & $85.98 \pm 31.83 \mathrm{a}$ & $89.25 \pm 47.34 \mathrm{a}$ & $64.51 \pm 19.66 \mathrm{a}$ \\
\hline $\mathrm{CEC}\left(\mathrm{cmol} \mathrm{kg}^{-1}\right)$ & $27.12 \pm 9.95 \mathrm{a}$ & $24.87 \pm 7.31 \mathrm{a}$ & $24.02 \pm 8.66 \mathrm{a}$ & $24.72 \pm 3.84 \mathrm{a}$ \\
\hline $\operatorname{MBC}\left(\mathrm{mg} \mathrm{kg}^{-1}\right)$ & $230.87 \pm 31.03 \mathrm{a}$ & $160.58 \pm 48.73 b$ & $103.45 \pm 53.51 b$ & $43.74 \pm 4.56 c$ \\
\hline $\mathrm{MBN}\left(\mathrm{mg} \mathrm{kg}^{-1}\right)$ & $64.41 \pm 27.98 \mathrm{a}$ & $53.80 \pm 18.78 b$ & $34.03 \pm 4.05 \mathrm{~b}$ & $23.48 \pm 2.86 \mathrm{c}$ \\
\hline $\operatorname{MBP}\left(\mathrm{mg} \mathrm{kg}^{-1}\right)$ & $6.95 \pm 1.41 \mathrm{a}$ & $3.34 \pm 0.65 \mathrm{a}$ & $4.22 \pm 0.80 \mathrm{~b}$ & $3.07 \pm 0.92 \mathrm{a}$ \\
\hline $\mathrm{BAC}\left(\times 10^{3} \mathrm{CFU} \mathrm{g}^{-1}\right)$ & $1.41 \pm 1.57 \mathrm{a}$ & $0.92 \pm 0.97 b$ & $1.22 \pm 1.39 \mathrm{a}$ & $0.46 \pm 0.17 \mathrm{a}$ \\
\hline FUN $\left(\times 10^{3} \mathrm{CFU} \mathrm{g}^{-1}\right)$ & $2.61 \pm 2.03 \mathrm{a}$ & $1.49 \pm 1.70 \mathrm{a}$ & $1.79 \pm 1.25 b$ & $2.09 \pm 2.29 \mathrm{a}$ \\
\hline $\mathrm{ACT}\left(\times 10^{3} \mathrm{CFU} \mathrm{g}^{-1}\right)$ & $7.37 \pm 14.64 \mathrm{a}$ & $2.05 \pm 1.88 b$ & $3.30 \pm 4.99 \mathrm{a}$ & $0.44 \pm 0.28 \mathrm{a}$ \\
\hline $\mathrm{BD}\left(\mathrm{g} \mathrm{cm}^{-3}\right)$ & $1.26 \pm 0.18 \mathrm{a}$ & $1.33 \pm 0.14 \mathrm{a}$ & $1.29 \pm 0.12 \mathrm{a}$ & $1.39 \pm 0.08 \mathrm{a}$ \\
\hline $\mathrm{CMC}(\%)$ & $0.33 \pm 0.04 \mathrm{a}$ & $0.36 \pm 0.09 \mathrm{a}$ & $0.38 \pm 0.05 \mathrm{a}$ & $0.33 \pm 0.03 \mathrm{a}$ \\
\hline $\mathrm{FMC}\left(\mathrm{g} \mathrm{g}^{-1}\right)$ & $0.26 \pm 0.08 \mathrm{a}$ & $0.28 \pm 0.09 \mathrm{a}$ & $0.27 \pm 0.09 \mathrm{a}$ & $0.25 \pm 0.03 \mathrm{a}$ \\
\hline CAP $(\%)$ & $0.42 \pm 0.09 \mathrm{a}$ & $0.46 \pm 0.06 \mathrm{a}$ & $0.48 \pm 0.04 b$ & $0.45 \pm 0.02 \mathrm{a}$ \\
\hline TOP (\%) & $0.52 \pm 0.07 \mathrm{a}$ & $0.50 \pm 0.05 a$ & $0.51 \pm 0.04 \mathrm{a}$ & $0.48 \pm 0.03 b$ \\
\hline
\end{tabular}

TOC, total organic carbon; TN, total nitrogen; TP, total phosphorus; AP, available phosphorus; TK, total potassium; AK, available potassium; CEC, cation exchange capacity; MBC, microbial biomass carbon; MBN, microbial biomass nitrogen; MBP, microbial mass phosphorus; BAC, bacteria; FUN, fungi; ACT, actinomycetes; BD, bulk density; CMC, capillary moisture capacity; FMC, field moisture capacity; CAP, capillary porosity; TOP, total porosity. Mean \pm SD within each row, for each indicator, followed by the same letter are not significantly different in ANOVA post hoc test at $p \leq 0.05$ after Bonferroni correction.

Table 3. Correlation matrix of soil evaluating indicators for rocky desertification ${ }^{\mathrm{a}}$.

\begin{tabular}{|c|c|c|c|c|c|c|c|c|c|c|c|c|c|c|c|c|c|c|}
\hline & $\mathrm{pH}$ & TOC & $\mathrm{TN}$ & $\mathrm{TP}$ & AP & TK & $\mathrm{AK}$ & CEC & MBC & MBN & MBP & BAC & FUN & ACT & $\mathrm{BD}$ & $\mathrm{CMC}$ & FMC & CAP \\
\hline TOC & -0.158 & 1 & & & & & & & & & & & & & & & & \\
\hline $\mathrm{TN}$ & 0.097 & $0.936^{\mathrm{c}}$ & 1 & & & & & & & & & & & & & & & \\
\hline TP & -0.049 & $0.555^{\mathrm{b}}$ & $0.678^{\mathrm{c}}$ & 1 & & & & & & & & & & & & & & \\
\hline $\mathrm{AP}$ & $-0.458^{\mathrm{b}}$ & 0.308 & 0.125 & -0.065 & 1 & & & & & & & & & & & & & \\
\hline TK & 0.357 & 0.009 & 0.116 & 0.406 & $-0.476^{\mathrm{b}}$ & 1 & & & & & & & & & & & & \\
\hline $\mathrm{AK}$ & 0.032 & -0.036 & -0.027 & 0.095 & 0.277 & 0.365 & 1 & & & & & & & & & & & \\
\hline CEC & 0.285 & 0.375 & $0.514^{\mathrm{b}}$ & 0.253 & -0.335 & 0.312 & 0.165 & 1 & & & & & & & & & & \\
\hline MBC & -0.188 & $0.678^{\mathrm{c}}$ & $0.514^{\mathrm{b}}$ & 0.049 & 0.255 & -0.056 & 0.046 & 0.175 & 1 & & & & & & & & & \\
\hline MBN & -0.036 & $0.530^{\mathrm{b}}$ & $0.536^{\mathrm{b}}$ & 0.274 & -0.037 & 0.000 & -0.052 & 0.118 & $0.690^{\mathrm{c}}$ & 1 & & & & & & & & \\
\hline MBP & -0.317 & 0.217 & 0.104 & -0.055 & 0.101 & -0.224 & -0.124 & 0.085 & $0.580^{\mathrm{c}}$ & 0.439 & 1 & & & & & & & \\
\hline BAC & 0.348 & 0.129 & 0.254 & 0.026 & -0.113 & -0.023 & 0.005 & $0.573^{c}$ & 0.150 & 0.242 & 0.192 & 1 & & & & & & \\
\hline FUN & -0.379 & -0.314 & $-0.463^{\mathrm{b}}$ & -0.205 & -0.001 & -0.029 & -0.021 & -0.361 & -0.064 & -0.054 & 0.218 & -0.240 & 1 & & & & & \\
\hline ACT & -0.233 & 0.090 & -0.062 & -0.032 & 0.227 & -0.106 & -0.052 & -0.100 & 0.277 & -0.062 & $0.602^{\mathrm{c}}$ & 0.059 & 0.380 & 1 & & & & \\
\hline $\mathrm{BD}$ & 0.100 & $-0.562^{\mathrm{c}}$ & $-0.548^{\mathrm{b}}$ & -0.332 & -0.093 & -0.233 & -0.310 & $-0.664^{\mathrm{c}}$ & -0.314 & -0.182 & -0.126 & -0.432 & 0.131 & 0.096 & 1 & & & \\
\hline CMC & 0.263 & 0.302 & $0.448^{\mathrm{b}}$ & $0.587^{\mathrm{c}}$ & $-0.455^{\mathrm{b}}$ & $0.577^{\mathrm{c}}$ & 0.266 & $0.534^{\mathrm{b}}$ & 0.094 & 0.379 & -0.035 & 0.361 & -0.113 & -0.061 & $-0.522^{\mathrm{b}}$ & 1 & & \\
\hline FMC & 0.278 & 0.236 & 0.404 & $0.447^{b}$ & $-0.641^{\mathrm{c}}$ & $0.526^{\mathrm{b}}$ & 0.112 & $0.664^{\mathrm{c}}$ & 0.099 & 0.442 & -0.020 & 0.402 & -0.147 & -0.282 & $-0.466^{\mathrm{b}}$ & $0.861^{\mathrm{c}}$ & 1 & \\
\hline CAP & 0.364 & -0.091 & 0.097 & 0.421 & $-0.613^{\mathrm{c}}$ & $0.474^{\mathrm{b}}$ & 0.101 & 0.173 & -0.125 & 0.308 & -0.096 & 0.135 & -0.033 & -0.011 & 0.107 & $0.787^{\mathrm{c}}$ & $0.681^{\mathrm{c}}$ & 1 \\
\hline TOP & -0.100 & $0.562^{\mathrm{c}}$ & $0.548^{\mathrm{b}}$ & 0.332 & 0.093 & 0.232 & 0.310 & $0.664^{\mathrm{c}}$ & 0.314 & 0.182 & 0.126 & 0.433 & -0.131 & -0.096 & $-1.000^{\mathrm{c}}$ & $0.522^{b}$ & $0.466^{\mathrm{b}}$ & -0.108 \\
\hline
\end{tabular}

\subsection{Correlation of integrate fertility scores with evaluating indicators}

The results in Table 5 demonstrated that the integrate fertility scores were strongly and significantly correlated to $\mathrm{CEC}$, MBC, MBN, CMC, FMC, and FMC $(p<0.01)$ and were significantly correlated to TOC and BD but were insignificantly correlated to $\mathrm{pH}, \mathrm{TP}, \mathrm{AP}, \mathrm{TK}, \mathrm{AK}, \mathrm{MBP}, \mathrm{BAC}, \mathrm{FUN}, \mathrm{ACT}$, and CAP.

\section{Discussions}

\subsection{Effects of succession of RD on soil fertility}

Table 2 clearly showed that the average values of TOC, TN, $\mathrm{AP}, \mathrm{MBC}$, and MBN perfectly matched the pre-defined succession of RD grades and those of TP and MBP showed a similar tendency. Thus, soil fertility decreased along with the aggravation of RD (Fig. 2). Soil fertility, as the basis of soil quality, directly affects the productivity of land. In return, land use type and frequency influence the soil qual- 
Table 4. Principal components analysis.

\begin{tabular}{lrrrrrr}
\hline \multirow{2}{*}{ Items } & \multicolumn{5}{c}{ Characteristic vector of principal component } \\
\cline { 2 - 7 } & $\mathrm{PC}_{1}-\mathrm{A}_{1}$ & $\mathrm{PC}_{2}-\mathrm{A}_{2}$ & $\mathrm{PC}_{3}-\mathrm{A}_{3}$ & $\mathrm{PC}_{4}-\mathrm{A}_{4}$ & $\mathrm{PC}_{5}-\mathrm{A}_{5}$ & $\mathrm{PC}_{6}-\mathrm{A}_{6}$ \\
\hline $\mathrm{pH}$ & 0.386 & 0.180 & -0.044 & -0.458 & -0.623 & 0.079 \\
TOC & -0.058 & 0.302 & $\mathbf{0 . 6 7 4}$ & -0.170 & 0.563 & 0.020 \\
$\mathrm{TP}$ & 0.477 & 0.055 & 0.207 & -0.174 & $\mathbf{0 . 6 6 2}$ & 0.088 \\
$\mathrm{AP}$ & -0.766 & -0.125 & 0.242 & 0.051 & 0.245 & 0.388 \\
$\mathrm{TK}$ & $\mathbf{0 . 6 9 0}$ & 0.080 & -0.139 & -0.075 & 0.095 & 0.427 \\
$\mathrm{AK}$ & 0.074 & 0.091 & -0.031 & -0.003 & 0.008 & $\mathbf{0 . 9 4 6}$ \\
$\mathrm{CEC}$ & 0.285 & $\mathbf{0 . 8 6 4}$ & 0.062 & -0.142 & 0.062 & 0.046 \\
MBC & -0.123 & 0.161 & $\mathbf{0 . 8 7 4}$ & 0.181 & 0.074 & 0.095 \\
MBN & 0.296 & 0.018 & $\mathbf{0 . 8 6 1}$ & 0.000 & 0.063 & -0.114 \\
MBP & -0.107 & 0.186 & $\mathbf{0 . 5 4 9}$ & $\mathbf{0 . 6 6 7}$ & -0.077 & -0.155 \\
$\mathrm{BAC}$ & 0.105 & $\mathbf{0 . 7 7 2}$ & 0.188 & -0.008 & -0.331 & -0.063 \\
FUN & 0.051 & -0.257 & -0.239 & $\mathbf{0 . 7 7 5}$ & 0.092 & -0.020 \\
ACT & -0.107 & 0.003 & 0.191 & $\mathbf{0 . 7 8 4}$ & -0.076 & 0.068 \\
$\mathrm{BD}$ & -0.039 & -0.778 & -0.125 & 0.010 & -0.461 & -0.256 \\
CMC & $\mathbf{0 . 8 1 8}$ & 0.371 & 0.164 & -0.032 & 0.213 & 0.189 \\
FMC & $\mathbf{0 . 8 0 0}$ & 0.458 & 0.139 & -0.128 & 0.131 & -0.046 \\
CAP & $\mathbf{0 . 9 2 2}$ & -0.098 & 0.089 & -0.009 & -0.108 & 0.025 \\
Eigenvalue & 4.957 & 3.259 & 1.894 & 1.605 & 1.380 & 0.965 \\
Variance contribution rate/\% & 29.162 & 19.169 & 11.138 & 9.439 & 8.119 & 5.678 \\
Cumulative variance proportion/\% & 29.162 & 48.330 & 59.468 & 68.907 & 77.027 & 82.705 \\
\hline
\end{tabular}

* Characteristic vectors being larger than 0.5 are in bold font.

Table 5. Correlation analysis of integrate fertility scores $(F)$ with soil indicators.

\begin{tabular}{rrrrrrrrrr}
\hline & $\mathrm{pH}$ & TOC & TP & AP & TK & AK & CEC & MBC & MBN \\
\hline$F$ & 0.047 & $0.511^{\mathrm{a}}$ & 0.337 & -0.109 & 0.233 & 0.305 & $0.654^{\mathrm{b}}$ & $0.607^{\mathrm{b}}$ & $0.682^{\mathrm{b}}$ \\
\hline & $\mathrm{MBP}$ & BAC & FUN & ACT & BD & CMC & FMC & CAP & \\
\hline$F$ & 0.440 & 0.387 & -0.143 & -0.033 & $-0.545^{\mathrm{a}}$ & $0.563^{\mathrm{b}}$ & $0.613^{\mathrm{b}}$ & 0.304 & \\
\hline
\end{tabular}

${ }^{\text {a }}$ Significant (two-tailed) at $p \leq 0.05$ level. ${ }^{\mathrm{b}}$ Significant (two-tailed) at $p \leq 0.01$ level.

ity (Ozgoz et al., 2013). The aggravation of RD is not only caused by anthropogenic factor (land overuse) but also by climate change (Li et al., 2009a). Degradation of phytocommunity (tree $\rightarrow$ tree/shrub $\rightarrow$ shrub $\rightarrow$ shrub/grass $\rightarrow$ grass) results in the homogenization of community structure, decrease of biomass and litter fall, and reduction of plant nutrition. The altered soil ecosystem leads to microorganism population reduction and microbial degradation of litter fall decrease, so that $\mathrm{C}, \mathrm{N}$, and $\mathrm{P}$ retentions in soil decrease (Lu et al., 2014). Subsequently, along with the aggravation of RD, a hardening of the soil, enlarging of bulk density, worsening of water/air permeability, and decreasing of the surface soil's water-holding ability would happen, and the strong surface runoff would cause a great loss of N, P, and K nutrients (Peng and Wang, 2012). In other words, multiple effects eventually lead to ISF decreasing with the aggravation of RD.

\subsection{Discordance between soil fertility level and RD grade in some sites}

Although the sequencing of the mean ISF scores was PRD $>$ LRD > MRD > IRD (Fig. 2), soil fertility fluctuated remarkably with different sampling sites and with different RD grades (Fig. 1). Soil fertility levels were not always consistent with RD grades; for instance, the fertilities of MRD in LH3, XH3, and XS3 sites were greater than those of LRD in $\mathrm{SD} 2, \mathrm{XH} 2$, and $\mathrm{XS} 2$ sites (Fig. 1). This might be ascribed to (i) the classification method of RD not being so correct. The actual soil fertility could not be only explored from soil depth, vegetation coverage, bedrock exposure, and vegetation type. Maybe the variables used were not enough to explain the level of RD. For some karst areas (MRD or IRD), although their vegetation covers are less than those of LRD, their surface fertile soil might accumulate in a low-lying zone when eroded by rainfall chronically; hence some soil with 


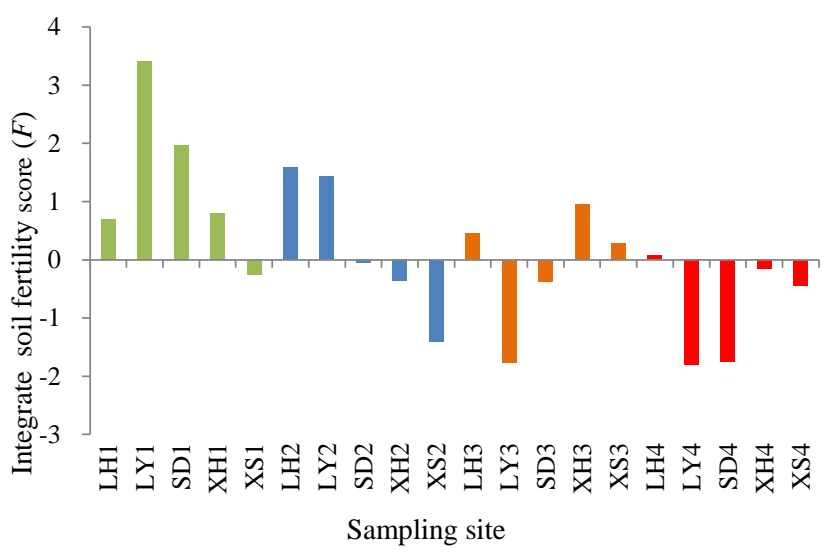

Figure 1. Integrate soil fertility scores of 20 studied plots. LH, $\mathrm{LY}, \mathrm{SD}, \mathrm{XH}$, and XS are the sampling plots standing for Longhui, Lianyuan, Shaodong, Xinhua, and Xinshao counties at central Hunan province, China, respectively. The green, blue, orange, and red bars refer to potential, light, moderate, and intensive rocky desertification, respectively.

higher RD grade would have greater fertility. (ii) Maybe climate variables, land use, topography of the studied area and soil type should be used in PCA and should also be considered in a future work to explain RD. The difference of soil fertility is also caused by regional variation. Local climate, soil-forming conditions, and the way and extent of anthropogenic intervention are different from one region to another (Clemens et al., 2010). Thus, soil fertility in one region for MRD might be greater than that in another region for LRD. When we investigated on stands, we found that the majority of PRD regions had better vegetation because they had been enclosed for afforestation to avoid anthropogenic interference. Most of the IRD regions became abandoned land without any agricultural production due to seriously degrading soil fertility. In contrast, both LRD and MRD regions with moderate fertility were not strictly protected. Perhaps residue burning had caused degradation of tree/shrub to shrub/grass or animal grazing had led to residue mineralization, recycling of faeces, and incrementing soil nutrients (McCarty et al., 2009; Shariff, 1994). They were usually utilized to cultivate timber forests or non-wood forests. Thus, this variable should be used in the model. As a result, the anthropogenic interference to LRD or MRD certainly reached the highest level. Human activity is one of key driving factors of $\mathrm{RD}$ ( $\mathrm{Li}$ et al., 2009b; Xiong et al., 2009), and RD grade varies among land use types ( $\mathrm{Li}$ et al., 2006). Therefore, reducing human activities and taking measurements such as mountain closure, forest reservation, and plantation might be some important measures to control expanding of RD area, which could be learned from natural vegetation rehabilitation to control soil erosion on the Loess Plateau (Zhao et al., 2013, 2015). (iii) Self-organization of soil environment improves soil fertility. With gradual deterioration of soil fertility, soil animals and

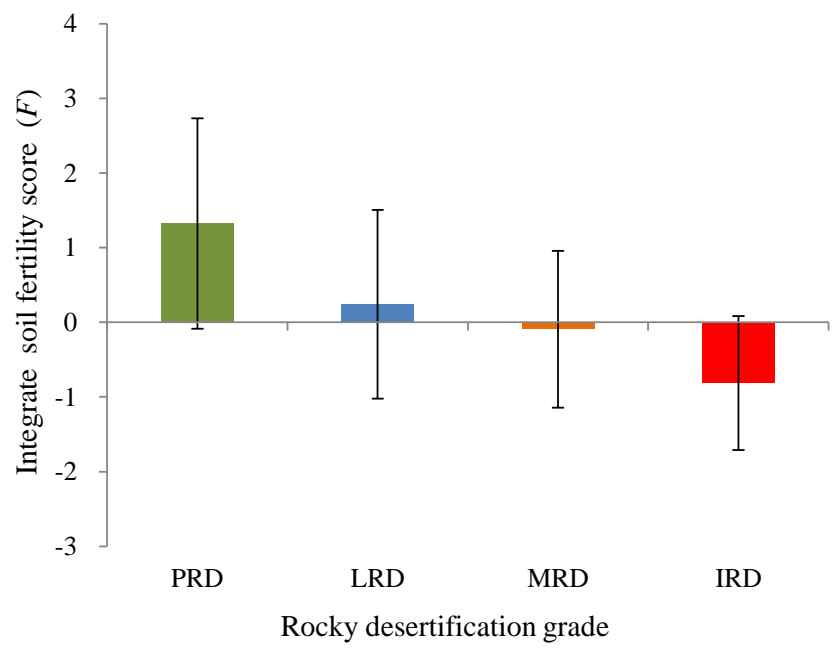

Figure 2. Average scores of integrate soil fertility of 20 studied plots. PRD, LRD, MRD, and IRD refer to potential, light, moderate, and intensive rocky desertification, respectively. Paired difference were analyzed as $p(\mathrm{LRD})=0.111, p(\mathrm{MRD})=0.254$, and $p($ IRD $)=0.097$ compared to PRD. The hanging bars refer to the standard deviation of the means.

microorganism at some stage (MRD) increase the speed of litter fall breakdown by disintegrating tissue and fixing the nutrients to acclimate the degrading environment (Barot et al., 2007). Thus, the fertility of MRD soil is likely greater than that of LRD soil.

\subsection{Sensitive indicators to evaluate soil fertility in RD lands}

Selecting appropriate indicators will guarantee the accuracy of evaluating results. Generally, evaluating indicators are chosen empirically based on the researching fruits of predecessors. Some physicochemical (Ozgoz et al., 2013), microbial biomass (Paz-Ferreiro and Fu, 2013), and enzymatic activity properties (Pajares et al., 2011) had been chosen to assess the soil fertility. On the basis of scientifically reliability, defining a minimum data set for evaluating soil fertility can cut down the number of indicators and reduce evaluating cost.

Soil organic matter (used interchangeably with TOC), as the major source of several nutrients, exerts numerous positive effects on soil physicochemical properties as well as soil's capacity to provide regulatory ecosystem services. $\mathrm{N}$, $\mathrm{P}$, and $\mathrm{K}$ are often referred to the primary macronutrients in soil for plants' growth. CEC is used as a measure of fertility and nutrient retention capacity. BD, as an indicator of soil compaction, reflects the extent of loosening and permeability of soil. MBC, MBN, and MBP reflect the number and activity of soil microorganism and the status of soil environment, although they only have a little content in soil with the mean ratios of $\mathrm{MBC}$ to TOC $(0.61 \%), \mathrm{MBN}$ to $\mathrm{TN}(2.16 \%)$, and 
MBP to TP $(0.95 \%)$ in this study (extracting from Table 2). It was reported that the microbial activity directly influences soil ecosystem stability and fertility (Pascual et al., 1997). Soil biochemical, microbiological, and biological properties are more suitable than physical and/or chemical properties to estimate soil quality and soil degradation (Paz-Ferreiro and $\mathrm{Fu}, 2013)$. And it is widely recognized that a good level of microbiological activity is crucial for maintaining soil quality (de la Paz Jimenez et al., 2002; Pascual et al., 2000; Visser and Parkinson, 1992), because microbial turnover is a driving force for transformation and cycling of organic matter to plant nutrients in soils (Chen and He, 2002; Fontaine et al., 2003). For instance, the change in $\mathrm{MBC}$ is a sensitive index of changes in the content of soil organic matter (GarcíaOrenes et al., 2010; Powlson et al., 1987), and it is useful for determining microbial population size to evaluate natural and degraded systems (Soulas et al., 1984). The strong and positive correlation between MBC and TOC (Table 3) indicated that $\mathrm{MBC}$ was a sensitive index to indicate the dynamics of soil organic carbon (Liu et al., 2012). Inorganic $\mathrm{N}$ and $\mathrm{P}$ needed by vegetation are mainly obtained from mineralization of organic matter in soil microbial degradation system (Hopkins et al., 2011; Ros et al., 2011). The changes in MBN and MBP can also indicate the fluctuation of soil fertility (Powlson et al., 1987). Thus, these indicators deserve prior researching before getting a minimum data set.

Furthermore, TOC, CEC, MBC, MBN, BD, CMC, and FMC were significantly correlated to the ISF $(p<0.05)$ (Table 5). Some of them (TOC, MBC, MBN) changed individually across the RD succession as expected (Table 2), while CEC, BD, CMC, and FMC did not changed at all across RD grades (Table 2). We could put forward that TOC, MBC, and MBN might be reasonable and sensitive indicators to estimate soil fertility in RD region. They could be included in the minimum data set of evaluating indicators for RD.

\section{Conclusions}

The succession of RD affected evaluating indicators of soil fertility to different extent, but the degradation trend of soil fertility was almost parallel to the aggravation of RD. Soil chemical indicators TOC and microbial indicators MBC and MBN might be the key indicators to evaluate soil fertility in $\mathrm{RD}$ regions according to their paired correlations and significant correlation to the ISF and changing tendency across the RD grades. Perhaps the method of classifying RD only according to soil depth and the landscape indicators (vegetation coverage, bedrock exposure, and vegetation type) could be improved after taking the regional difference of soil fertility into account in the future research.

Acknowledgements. This research was supported by National Department Public Benefit Research Foundation of State Forestry Administration of China (201104016) and the Planned Science and
Technology Project of Hunan Province, China (2013RS4035), and was partially funded by the China Postdoctoral Science Foundation (2013M531787). We thank Dr. Veronika for her critical revision of the manuscript. We are grateful to the Forestry Bureau of Lianyuan, Longhui, Shaodong, Xinhua, and Xinshao counties of Hunan for providing the sampling sites. We also acknowledge the anonymous reviewers for the valuable comments.

Edited by: A. Jordán

\section{References}

Bai, X. Y., Wang, S. J., and Xiong, K. N.: Assessing spatialtemporal evolution processes of karst rocky desertification land: Indications for restoration strategies, Land Degrad. Dev., 24, 4756, 2013.

Barot, S., Rossi, J. P., and Lavelle, P.: Self-organization in a simple consumer-resource system, the example of earthworms, Soil Biol. Biochem., 39, 2230-2240, 2007.

Bower, C. A., Reitmeir, R. F., and Fireman, M.: Exchangeable cation analysis of saline and alkali soils, Soil Sci., 73, 251-261, 1952.

Brookes, P. C., Kragt, J. F., Powlson, D. S., and Jenkinson, D. S.: Chloroform fumigation and the release of soil nitrogen: The effects of fumigation time and temperature, Soil Biol. Biochem., 17, 831-835, 1985a.

Brookes, P. C., Landman, A., Pruden, G., and Jenkinson, D. S.: Chloroform fumigation and the release of soil nitrogen: A rapid direct extraction method to measure microbial biomass nitrogen in soil, Soil Biol. Biochem., 17, 837-842, 1985b.

Bulluck III, L. R., Brosius, M., Evanylo, G. K., and Ristaino, J. B.: Organic and synthetic fertility amendments influence soil microbial, physical and chemical properties on organic and conventional farms, Appl. Soil Ecol., 19, 147-160, 2002.

Chen, G. C. and He, Z. L.: Microbial biomass phosphorus turnover in variable-charge soils in China, Commun. Soil Sci. Plant, 33, 2101-2117, 2002.

Cerdà, A. and Lavée, H.: The effect of grazing on soil and water losses under arid and Mediterranean climates. Implications for desertification, Pirineos, 153, 159-174, 1999.

Clemens, G., Fiedler, S., Cong, N. D., Van Dung, N., Schuler, U., and Stahr, K.: Soil fertility affected by land use history, relief position, and parent material under a tropical climate in NWVietnam, Catena, 81, 87-96, 2010.

de la Paz Jimenez, M., de la Horra, A., Pruzzo, L., and Palma, M.: Soil quality: a new index based on microbiological and biochemical parameters, Biol. Fert. Soils, 35, 302-306, 2002.

Deng, Y. and Jiang, Z. C.: Characteristic of rocky desertification and comprehensive improving model in karst peak-cluster depression in Guohua, Guangxi, China, Procedia Environmental Sciences, 10, 2449-2452, 2011.

Fallahzade, J. and Hajabbasi, M. A.: The effects of irrigation and cultivation on the quality of desert soil in central Iran, Land Degrad. Dev., 23, 53-61, 2012.

Fontaine, S., Mariotti, A., and Abbadie, L.: The priming effect of organic matter: a question of microbial competition?, Soil Biol. Biochem., 35, 837-843, 2003. 
Fu, B., Li, S., Yu, X., Yang, P., Yu, G., Feng, R., and Zhuang, X.: Chinese ecosystem research network: Progress and perspectives, Ecol. Complex., 7, 225-233, 2010.

García, L. V.: Escaping the Bonferroni iron claw in ecological studies, Oikos, 105, 657-663, 2004.

García-Orenes, F., Guerrero, C., Roldán, A., Mataix-Solera, J., Cerdà, A., Campoy, M., Zornoza, R., Bárcenas, G., and Caravaca, F.: Soil microbial biomass and activity under different agricultural management systems in a semiarid Mediterranean agroecosystem, Soil and Tillage Research, 109, 110-115, 2010.

Hopkins, D. W., Waite, I. S., and O'Donnell, A. G.: Microbial biomass, organic matter mineralization and nitrogen in soils from long-term experimental grassland plots (Palace Leas meadow hay plots, UK), Eur. J. Soil Sci., 62, 95-104, 2011.

Hu, Z. Q., He, F. Q., Yin, J. Z., Lu, X., Tang, S. L., Wang, L. L., and Li, X. J.: Estimation of fractional vegetation cover based on digital camera survey data and a remote sensing model, Journal of China University of Mining and Technology, 17, 116-120, 2007.

Huang, Q. H. and Cai, Y. L.: Spatial pattern of karst rock desertification in the middle of Guizhou province, southwestern China, Environ. Geol., 52, 1325-1330, 2007.

Huang, Q. H., Cai, Y. L., and Xing, X. S.: Rocky desertification, antidesertification, and sustainable development in the karst mountain region of Southwest China, Ambio, 37, 390-392, 2008.

Jaiyeoba, I. A.: Soil rehabilitation through afforestation: evaluation of the performance of Eucalyptus and pine plantations in a Nigerian Savanna environment, Land Degrad. Dev., 12, 183 194, 2001.

Li, C., Xiong, K., and Wu, G.: Process of biodiversity research of Karst areas in China, Acta Ecologica Sinica, 33, 192-200, 2013.

Li, G., Chen, J., Sun, Z., and Tan, M.: Establishing a minimum dataset for soil quality assessment based on soil properties and land-use changes, Acta Ecologica Sinica, 27, 2715-2724, 2007.

Li, S., Wei, X., Huang, J., Wang, X., Lu, G., and Li, H.: The causes and processes responsible for rocky desertification in karst areas of southern China, Sciences in Cold and Arid Regions, 1, 00800090, 2009a.

Li, Y. B., Bai, X. Y., and Qiu, X. C.: The correlation analysis of desertification of karst rock and land use patterns, Resources Science, 28, 68-73, 2006 (in Chinese with English abstract).

Li, Y. B., Shao, J. A., Yang, H., and Bai, X. Y.: The relations between land use and karst rocky desertification in a typical karst area, China, Environ. Geol., 57, 621-627, 2009b.

Liu, N., Zhang, Y., Chang, S., Kan, H., and Lin, L.: Impact of grazing on soil carbon and microbial biomass in typical steppe and desert steppe of Inner Mongolia, PLoS ONE, 7, e36434, doi:10.1371/journal.pone.0036434, 2012

Liu, R. X., Kuang, J., Gong, Q., and Hou, X. L.: Principal component regression analysis with SPSS, Comput. Meth. Prog. Bio., 71, 141-147, 2003.

Liu, Z.-F., Fu, B.-J., Liu, G.-H., and Zhu, Y.-G.: Soil quality: concept, indicators and its assessment, Acta Ecologica Sinica, 26, 901-913, 2006 (in Chinese with English abstract).

Lu, X., Toda, H., Ding, F., Fang, S., Yang, W., and Xu, H.: Effect of vegetation types on chemical and biological properties of soils of karst ecosystems, Eur. J. Soil Biol., 61, 49-57, 2014.

McCarty, J., Korontzi, S., Justice, C., and Loboda, T.: The spatial and temporal distribution of crop residue burning in the contiguous United States, Sci. Total Environ. 407, 5701-5712, 2009.
Ozgoz, E., Gunal, H., Acir, N., Gokmen, F., Birol, M., and Budak, M.: Soil quality and spatial variability assessment of land use effects in a tipic Haplustoll, Land Degrad. Dev., 24, 277-286, 2013.

Pajares, S., Gallardo, J. F., Masciandaro, G., Ceccanti, B., and Etchevers, J. D.: Enzyme activity as an indicator of soil quality changes in degraded cultivated Acrisols in the Mexican Transvolcanic Belt, Land Degrad. Dev., 22, 373-381, 2011.

Pascual, J. A., García, C., Hernandez, T., and Ayuso, M.: Changes in the microbial activity of an arid soil amended with urban organic wastes, Biol. Fert. Soils, 24, 429-434, 1997.

Pascual, J. A., Garcia, C., Hernandez, T., Moreno, J. L., and Ros, M.: Soil microbial activity as a biomarker of degradation and remediation processes, Soil Biol. Biochem., 32, 1877-1883, 2000.

Paz-Ferreiro, J. and Fu, S.: Biological indices for soil quality evaluation: perspectives and limitations, Land Degrad. Dev., in press, doi:10.1002/ldr.2262, 2013.

Peng, T. and Wang, S.-J.: Effects of land use, land cover and rainfall regimes on the surface runoff and soil loss on karst slopes in southwest China, Catena, 90, 53-62, 2012.

Powlson, D. S., Prookes, P. C., and Christensen, B. T.: Measurement of soil microbial biomass provides an early indication of changes in total soil organic matter due to straw incorporation, Soil Biol. Biochem., 19, 159-164, 1987.

Rice, W. R.: Analyzing tables of statistical tests, Evolution, 43, 223 225, 1989.

Ros, G. H., Temminghoff, E. J. M., and Hoffland, E.: Nitrogen mineralization: a review and meta-analysis of the predictive value of soil tests, Eur. J. Soil Sci., 62, 162-173, 2011.

Shariff, A. R.: Grazing intensity effects on litter decomposition and soil nitrogen mineralization, J. Range. Manage., 47, 444-449, 1994.

Sims, J.: Comparison of mehlich 1 and mehlich 3 extractants for $\mathrm{P}$, $\mathrm{K}, \mathrm{Ca}, \mathrm{Mg}, \mathrm{Mn}, \mathrm{Cu}$ and $\mathrm{Zn}$ in atlantic coastal plain soils, Commun. Soil Sci. Plan., 20, 1707-1726, 1989.

Smith, B. F. L. and Bain, D. C.: A sodium hydroxide fusion method for the determination of total phosphate in soils, Commun. Soil Sci. Plan., 13, 185-190, 1982.

Soulas, G., Chaussod, R., and Verguet, A.: Chloroform fumigation technique as a means of determining the size of specialized soil microbial populations: Application to pesticide-degrading microorganisms, Soil Biol. Biochem., 16, 497-501, 1984.

Tilman, D., Cassman, K. G., Matson, P. A., Naylor, R., and Polasky, S.: Agricultural sustainability and intensive production practices, Nature, 418, 671-677, 2002.

Visser, S. and Parkinson, D.: Soil biological criteria as indicators of soil quality: Soil microorganisms, Am. J. Alternative Agr., 7, 33-37, 1992.

Wang, H. and Jia, X.: Field observations of windblown sand and dust in the Takimakan Desert, NW China, and insights into modern dust sources, Land Degrad. Dev., 24, 323-333, 2013.

Wang, S. and Li, Y.: Problems and development trends about researches on karst rocky desertification, Advances in Earth Science, 22, 573-582, 2007 (in Chinese with English abstract).

Wang, S. J., Li, R. L., Sun, C. X., Zhang, D. F., Li, F. Q., Zhou, D. Q., Xiong, K. N., and Zhou, Z. F.: How types of carbonate rock assemblages constrain the distribution of karst rocky desertified land in Guizhou Province, PR China: phenomena and mechanisms, Land Degrad. Dev., 15, 123-131, 2004a. 
Wang, S. J., Liu, Q. M., and Zhang, D. F.: Karst rocky desertification in southwestern China: Geomorphology, landuse, impact and rehabilitation, Land Degrad. Dev., 15, 115-121, 2004b.

Wang, T., Yan, C. Z., Song, X., and Li, S.: Landsat images reveal trends in the aeolian desertification in a source area for sand and dust storms in China's Alashan Plateau (1975-2007), Land Degrad. Dev., 24, 422-429, 2013a.

Wang, X., Wang, G., Lang, L., Hua, T., and Wang, H.: Aeolian transport and sandy desertification in semiarid China: a wind tunnel approach, Land Degrad. Dev., 24, 605-612, 2013 b.

White, M. A., Asner, G. P., Nemani, R. R., Privette, J. L., and Running, S. W.: Measuring fractional cover and leaf area index in arid ecosystems: digital camera, radiation transmittance, and laser altimetry methods, Remote Sens. Environ., 74, 45-57, 2000.

Wu, J., Joergensen, R. G., Pommerening, B., Chaussod, R., and Brookes, P. C.: Measurement of soil microbial biomass C by fumigation-extraction-an automated procedure, Soil Biol. Biochem., 22, 1167-1169, 1990.

Wu, X. Q., Liu, H. M., Huang, X. L., and Zhou, T.: Human driving forces: Analysis of rocky desertification in karst region in Guanling County, Guizhou Province, Chinese Geogr. Sci., 21, 600-608, 2011.

Xie, L. and Wang, S.: Variations of nutrient element contents of plants and soils in the process of karst rocky desertification, Chin. J. Geochem., 25, 176-176, 2006.
Xiong, Y. J., Qiu, G. Y., Mo, D. K., Lin, H., Sun, H., Wang, Q. X., Zhao, S. H., and Yin, J.: Rocky desertification and its causes in karst areas: a case study in Yongshun County, Hunan Province, China, Environ. Geol., 57, 1481-1488, 2009.

Yan, X. and Cai, Y. L.: Multi-scale anthropogenic driving forces of karst rocky desertification in southwest China, Land Degrad. Dev., 26, 193-200, 2015.

Yao, R., Yang, J., Gao, P., Zhang, J., and Jin, W.: Determining minimum data set for soil quality assessment of typical salt-affected farmland in the coastal reclamation area, Soil and Tillage Research, 128, 137-148, 2013.

Yeomans, J. C. and Bremner, J. M.: A rapid and precise method for routine determination of organic carbon in soil, Commun.Soil Sci. Plan., 19, 1467-1476, 1988.

Zhao, G., Mu, X., Wen, Z., Wang, F., and Gao, P.: Soil erosion, conservation, and eco-environment changes in the Loess plateau of China, Land Degrad. Dev., 24, 499-510, 2013.

Zhao, X., Wu, P., Gao, X., Persaud, N.: Soil quality indicators in relation to land use and topography in a small catchment on the Loess Plateau of China, Land Degrad. Dev., 26, 54-61, 2015.

Zou, Z., Qiu, R., Zhang, W., Dong, H., Zhao, Z., Zhang, T., Wei, X., and Cai, X.: The study of operating variables in soil washing with EDTA, Environ. Pollut., 157, 229-236, 2009. 